\title{
A thermal-dissociation-cavity ring-down spectrometer (TD-CRDS) for the detection of organic nitrates in gas and particle phases
}

Natalie I. Keehan et al.

Correspondence to: Juliane L. Fry (fry@ reed.edu)

The copyright of individual parts of the supplement might differ from the CC BY 4.0 License. 


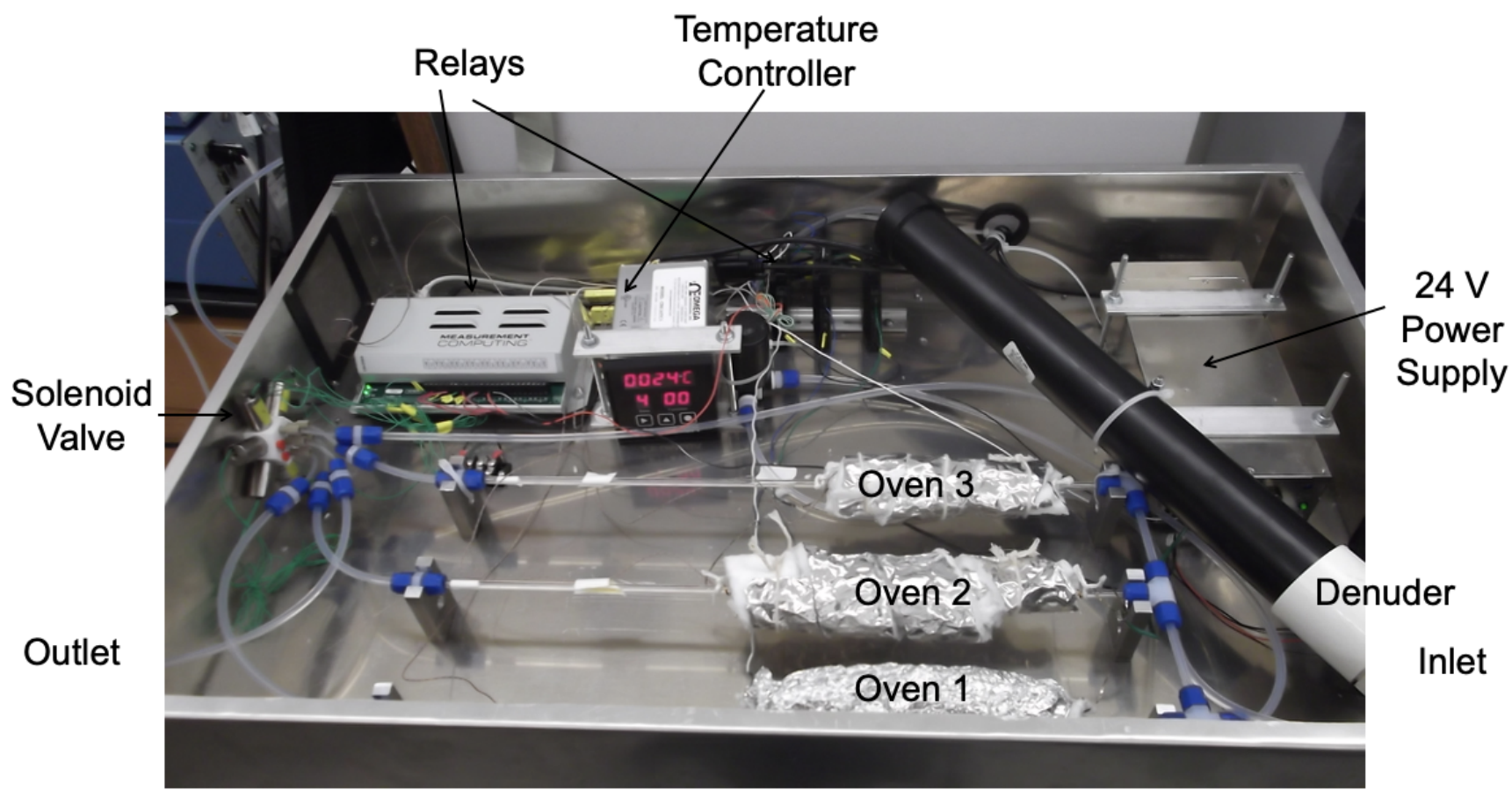

615

Figure S1. Oven inlet box. 

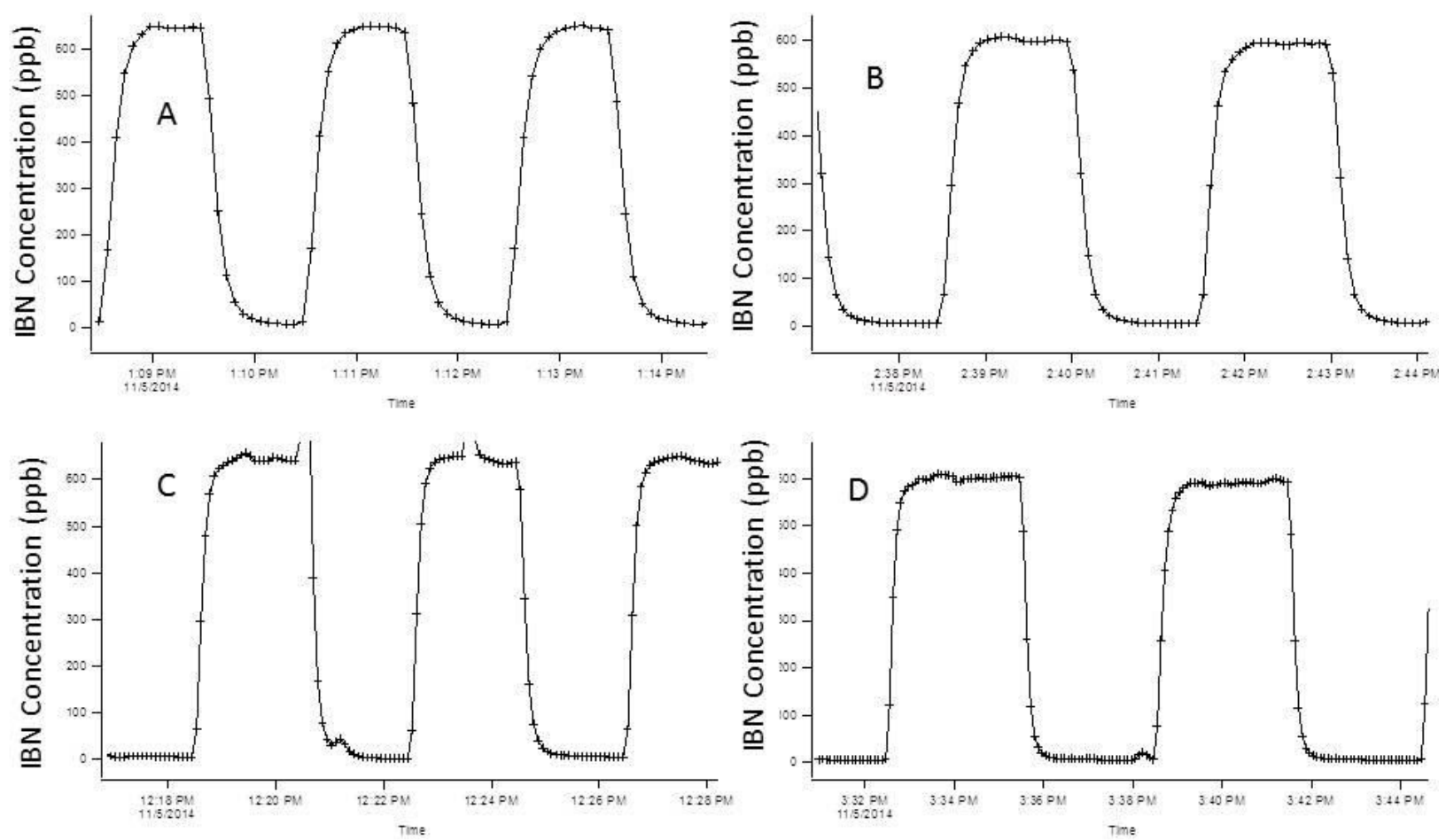

Figure S2. Channel switching frequency testing. Panel A shows 30 second sampling time, B 45 seconds, C 60 seconds, and 620 D 90 seconds. 

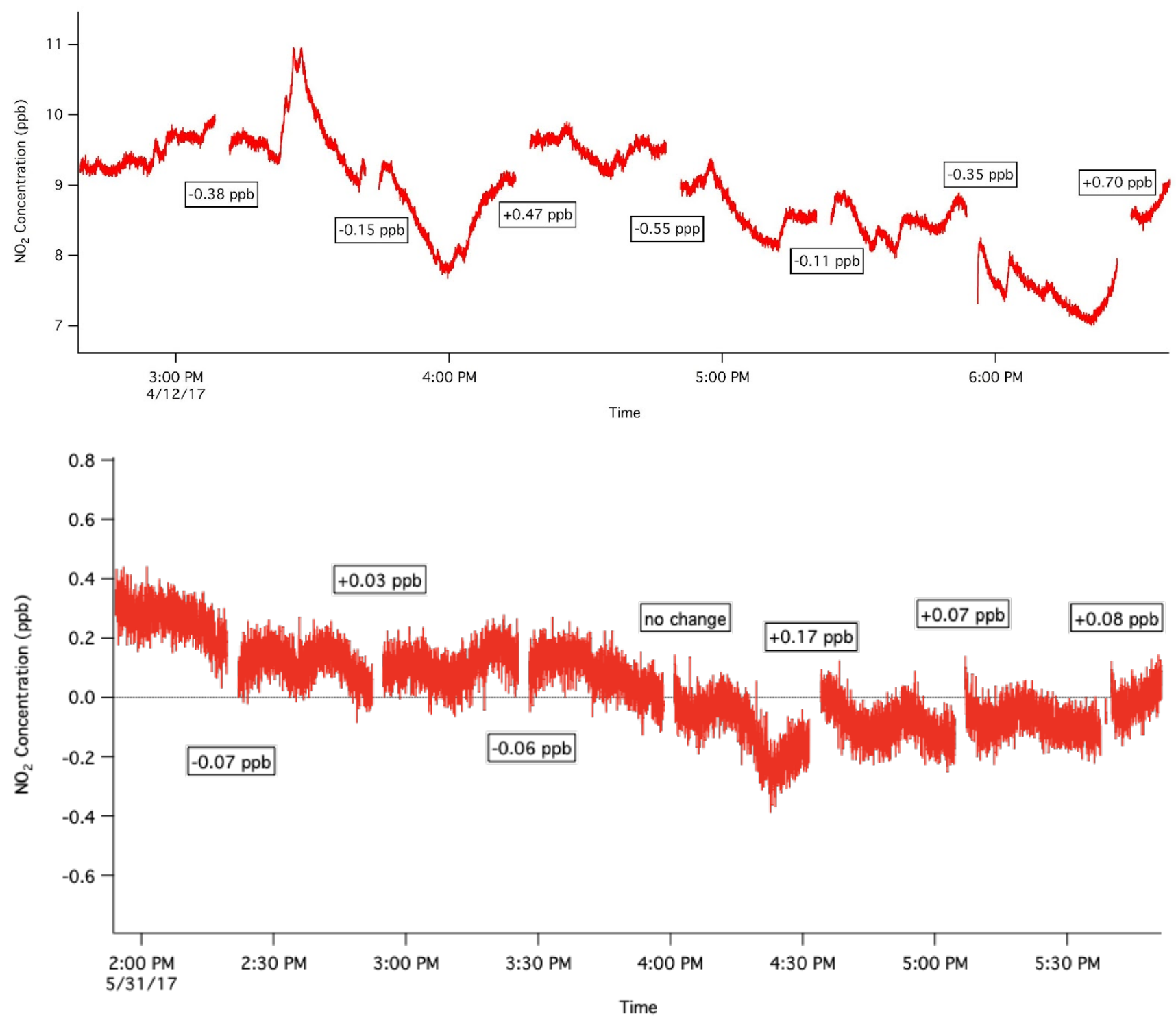

Figure S3. CRDS running for 4 hours on room air (upper panel) or zero air (lower panel). Seven instrument zeroes are visible across each timeseries to show the typical changes in signal. For the detection limit analysis included in the manuscript, the standard deviation of the zero signal measured over the full length of the lower panel was calculated, and found to be $\sigma_{\text {zero }}=$ $0.16 \mathrm{ppb}$. 
Table S1. Rate constants for different species used in kinetics model.

\begin{tabular}{|c|c|c|c|c|c|c|c|}
\hline \multirow{2}{*}{$\begin{array}{l}\text { Dissociation } \\
\text { Recombination } \\
\text { Reactions }\end{array}$} & \multicolumn{3}{|c|}{$\begin{array}{l}\text { Dissociation rate parameters (Day et al., } \\
\text { 2002, Table 1) }\end{array}$} & \multicolumn{4}{|c|}{$\begin{array}{l}\text { Recombination parameters ("JPL Data } \\
\text { Evaluation" 2015, Table 2-1) }\end{array}$} \\
\hline & $\mathrm{k}_{\mathrm{o}}^{\mathrm{a}}$ & $\mathrm{kh}^{\mathrm{b}}$ & $\mathrm{b}^{\mathrm{b}}$ & $\mathrm{k}_{\mathrm{o}}^{300, \mathrm{c}}$ & $\mathrm{n}^{\mathrm{c}}$ & $\mathrm{k}_{\infty}^{300, \mathrm{~d}}$ & $\mathrm{~m}^{\mathrm{d}}$ \\
\hline $\begin{array}{l}\mathrm{PN} \leftrightarrow \quad \mathrm{NO}_{2} \quad+ \\
\mathrm{CH}_{3} \mathrm{C}(\mathrm{O}) \mathrm{OO}\end{array}$ & $4.9 \times 10^{-3}$ & $4 \times 10^{16}$ & 13600 & $9.7 \times 10^{-29}$ & 5.6 & $9.3 \times 10^{-12}$ & 1.5 \\
\hline $\begin{array}{l}\mathrm{AN} \leftrightarrow \mathrm{NO}_{2}+\mathrm{C}_{2} \mathrm{H}_{5} \mathrm{CO} \text { or } \\
\mathrm{C}_{3} \mathrm{H}_{7} \mathrm{O}\end{array}$ & - & $3.16 \times 10^{16}$ & 20129 & $2 \times 10^{-27}$ & 4 & $2.8 \times 10^{-11}$ & 1 \\
\hline Loss Reaction & Rate constant & & & & & & \\
\hline $\mathrm{OH} \rightarrow$ walls $^{\mathrm{e}}$ & $46 \mathrm{~s}^{-1}$ & & & & & & \\
\hline $\begin{array}{l}\mathrm{n}-\mathrm{C}_{4} \mathrm{H}_{9} \mathrm{O} \\
\text { products }^{\mathrm{f}}\end{array}$ & $\left(8.9 \times 10^{-14}\right)\left(\mathrm{e}^{-550 / \mathrm{T}}\right) \mathrm{cm}^{3} \mathrm{~m}$ & lecule ${ }^{-1} \mathrm{~s}^{-1}$ & & & & & \\
\hline
\end{tabular}

630 a. Low pressure limit $\mathrm{k}_{0}(\mathrm{~T})=\mathrm{k}_{0} \exp (-\mathrm{a} / \mathrm{T})$, where $\mathrm{T}$ is temperature in Kelvin, $\mathrm{cm}^{3}$ molecule $\mathrm{e}^{-1} \mathrm{~s}^{-1}$

b. High pressure limit $\mathrm{k}_{\mathrm{h}}(\mathrm{T})=\mathrm{k}_{\mathrm{h}} \exp (-\mathrm{b} / \mathrm{T})$, where $\mathrm{T}$ is temperature in Kelvin, $\mathrm{cm}^{3}$ molecule ${ }^{-1} \mathrm{~s}^{-1}$

c. Low pressure limit $\mathrm{k}_{\mathrm{o}}(\mathrm{T})=\mathrm{k}_{\mathrm{o}}{ }^{300}(\mathrm{~T} / 300)^{-\mathrm{n}}$, where $\mathrm{T}$ is temperature in Kelvin, $\mathrm{cm}^{3}$ molecule $\mathrm{e}^{-1} \mathrm{~s}^{-1}$

d. High pressure limit $\mathrm{k}_{\infty}(\mathrm{T})=\mathrm{k}_{\infty}{ }^{300}(\mathrm{~T} / 300)^{-\mathrm{m}}$, where $\mathrm{T}$ is temperature in Kelvin, $\mathrm{cm}^{3}$ molecule $\mathrm{e}^{-1} \mathrm{~s}^{-1}$

e. Knopf, Pöschl, and Shiraiwa 2015

635 f. IUPAC evaluation, reaction RO_5, http://iupac.pole-ether.fr/ 


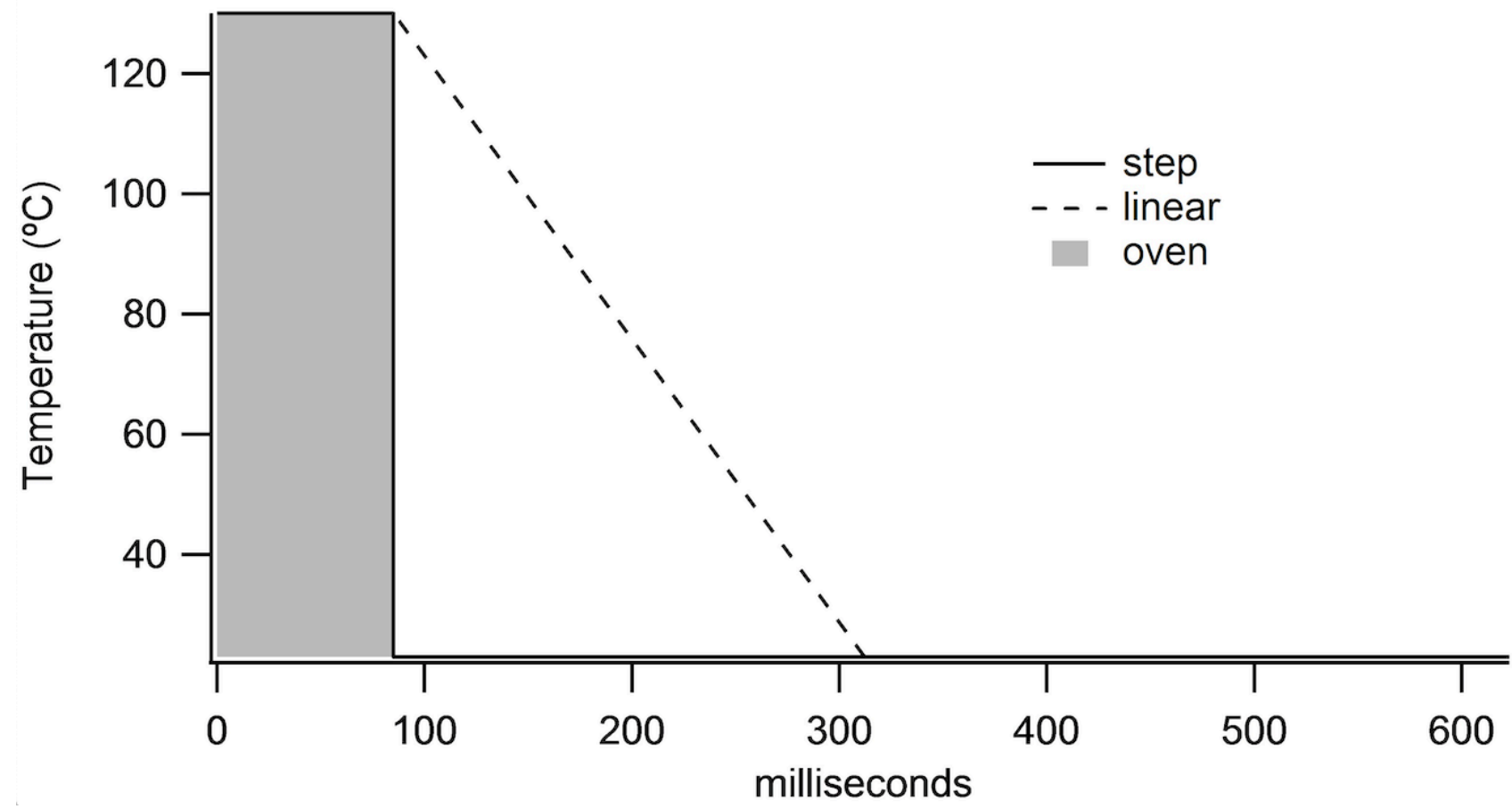

Figure S4. Two considered models of cooling rates in the quartz tubing after the PN oven. 

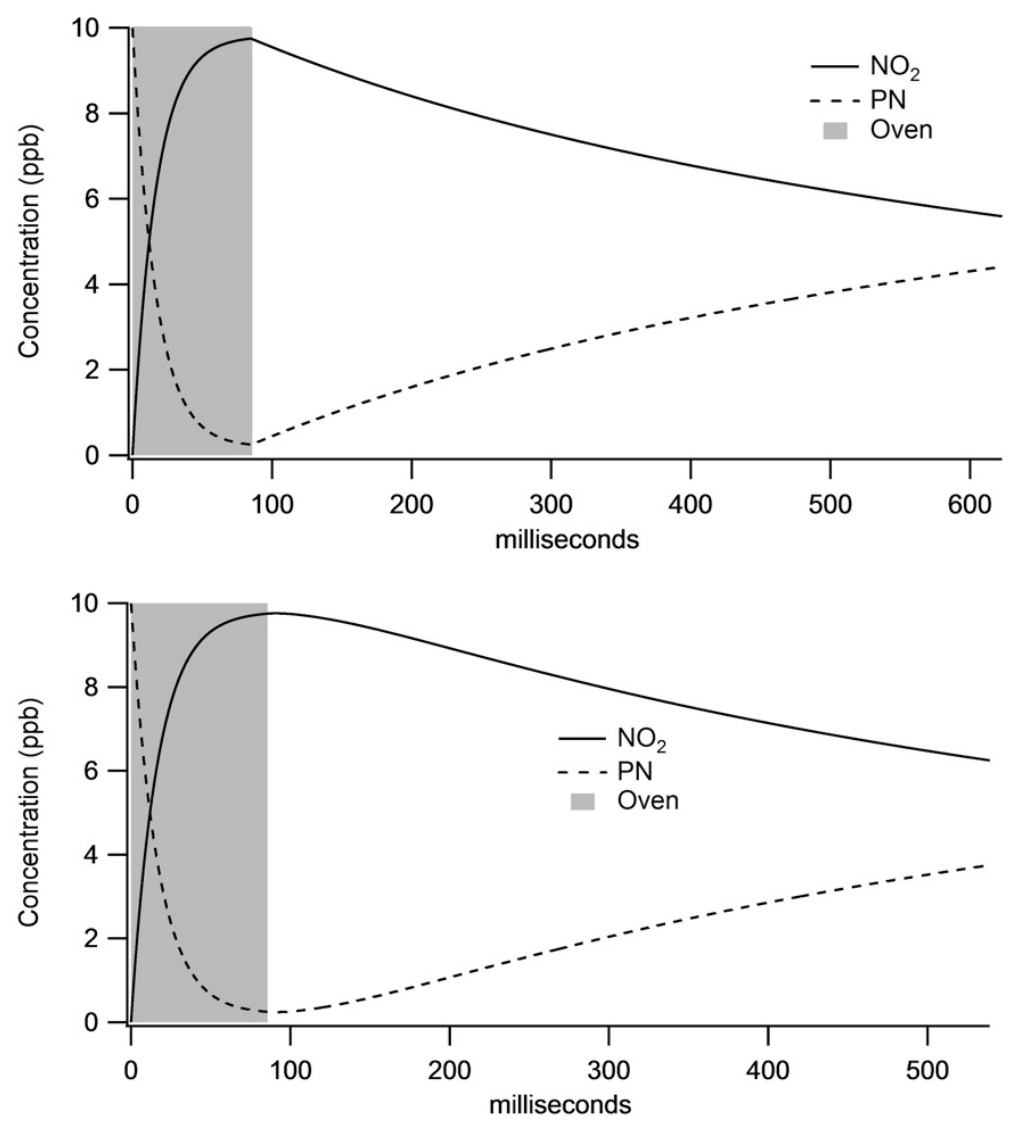

Figure S5. Model of PN dissociation through an oven at $120^{\circ} \mathrm{C}$, using both step function (top) and linear temperature decay (bottom). Shaded region is the heated portion of the oven. 


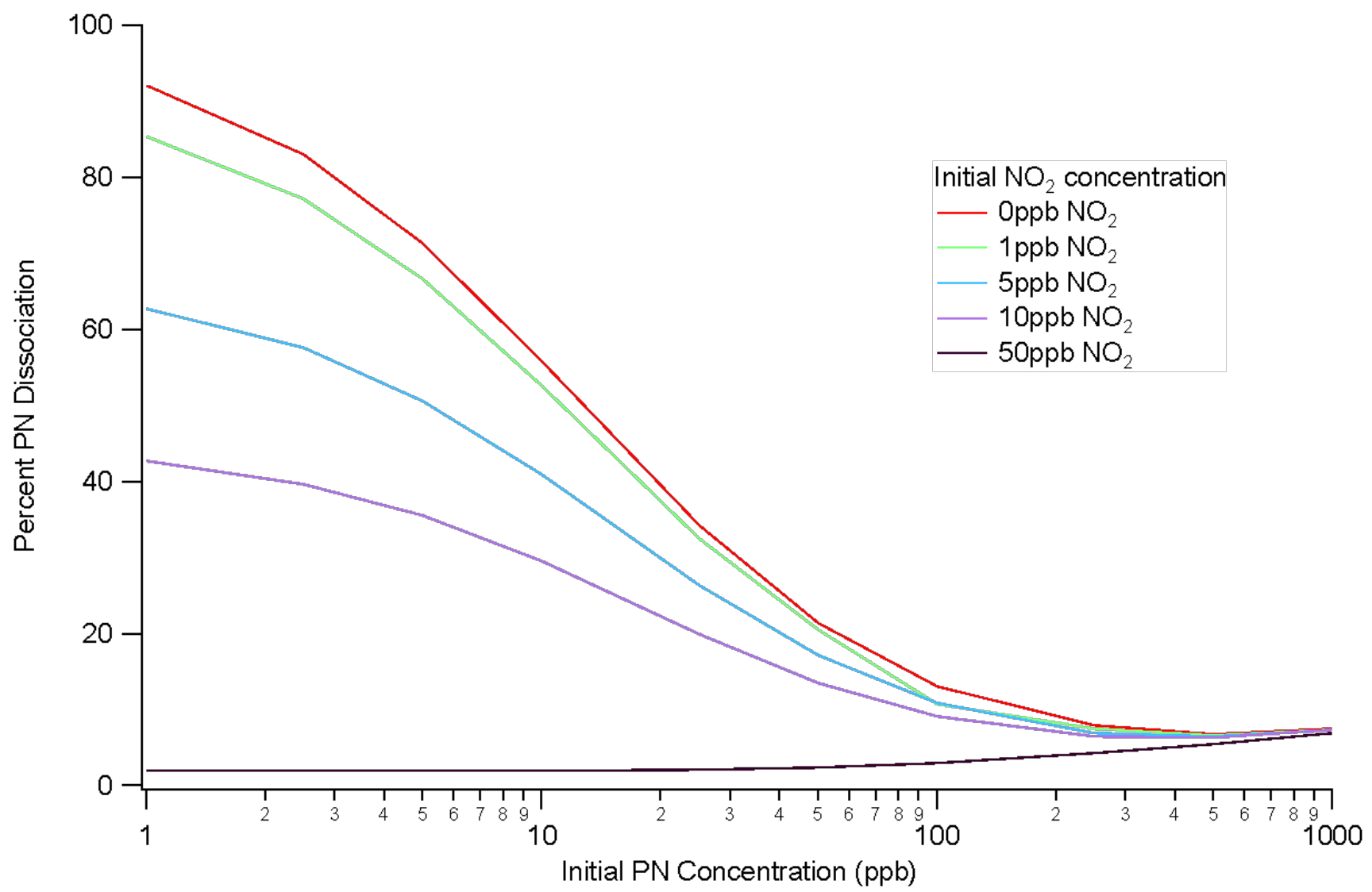

645 Figure S6. Percent PNs detected at CRDS at different initial concentrations of PNs and $\mathrm{NO}_{2}$. Most work is done in the lower concentration range of both $\mathrm{PNs}$ and $\mathrm{NO}_{2}$, where the percent of $\mathrm{PNs}$ that remain dissociated to the detector is relatively higher; however we note the recombination effect here is larger than for $\mathrm{ANs}$ or $\mathrm{HNO}_{3}$ (see Figure S7). Percent dissociated is equivalent to percent detected. 


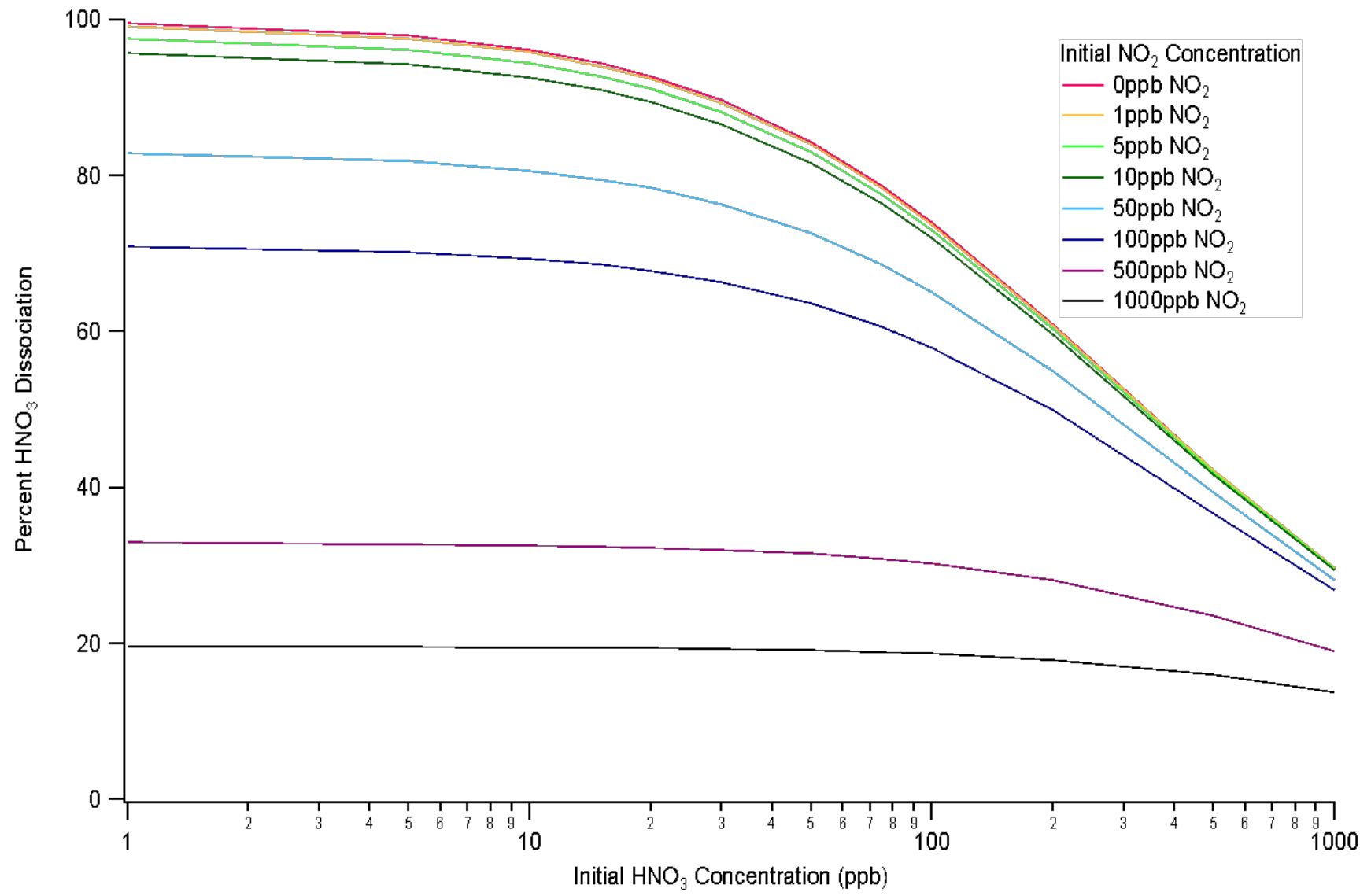

Figure S7. Percent $\mathrm{HNO}_{3}$ detected at CRDS at different initial concentrations of nitric acid and $\mathrm{NO}_{2}$. Most work is done in the lower concentration range of both $\mathrm{HNO}_{3}$ and $\mathrm{NO}_{2}$, where the percent $\mathrm{HNO}_{3}$ that remains dissociated to the detector is high. Percent dissociated is equivalent to percent detected. 


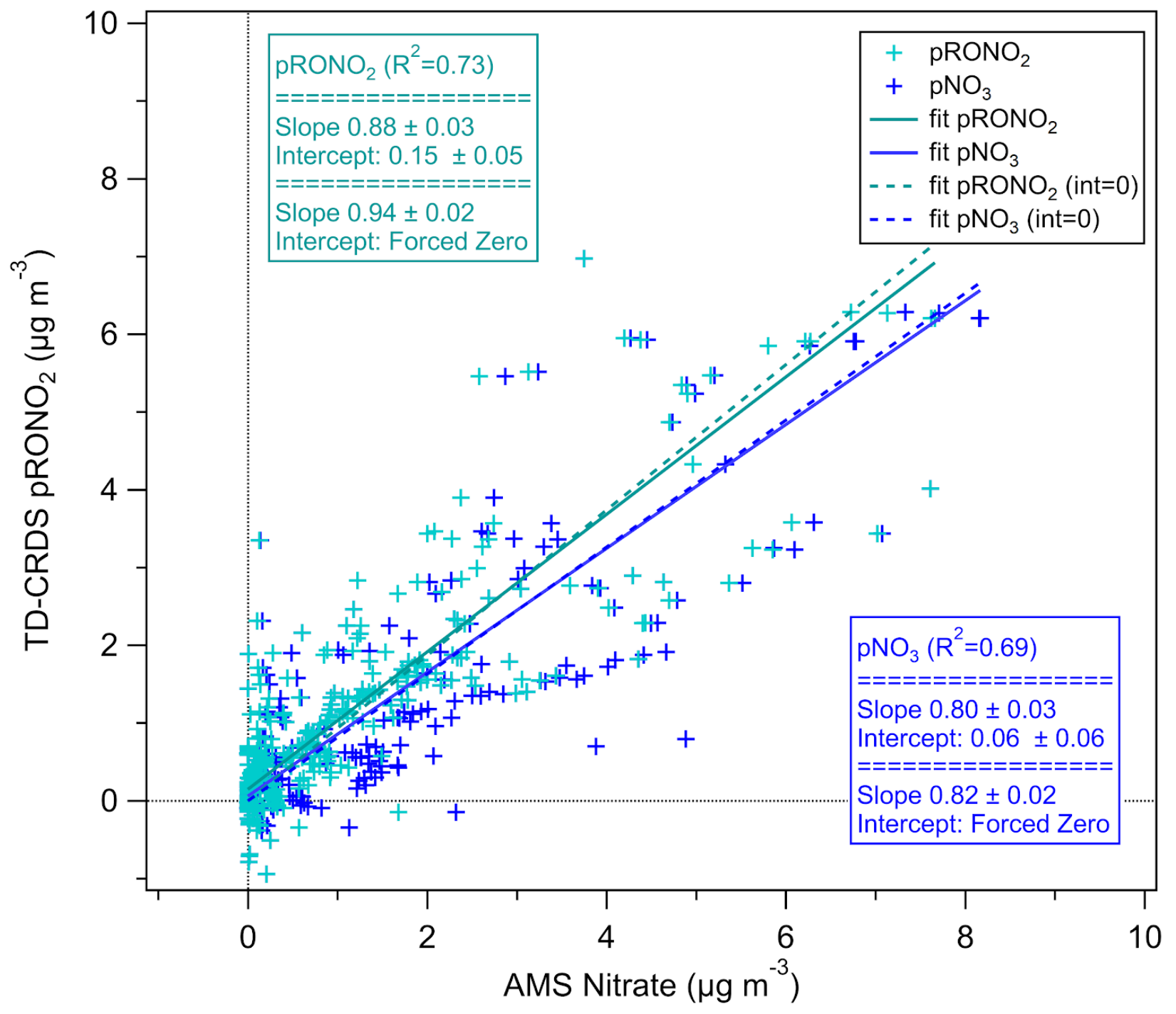

Figure S8. TD-CRDS organic nitrate vs AMS total nitrate $\left(\mathrm{pNO}_{3}\right)$ and apportioned organic nitrate fraction $\left(\mathrm{pRONO}_{2}\right)$. 